\title{
ЭКОНОМИЧЕСКИЙ КРИЗИС И ОЦЕНКА ЭФФЕКТИВНОСТИ ВЛАСТИ: КТО НЕСЕТ ОТВЕТСТВЕННОСТЬ ЗА УХУДШЕНИЕ УРОВНЯ ЖИЗНИ В РОССИИ?
}

\begin{abstract}
Винить или не винить власть за последствия экономического кризиса? Если обвинять, то кого граждане считают ответственным за проблемы в экономике в первую очередь? Мы предполагаем, что кризис и оценка эффективности работы органов власти связаны логикой атрибуции ответственности, то есть способностью людей определять центры принятия решений и устанавливать связь между политическим курсом и изменениями в реальности. На основе материалов всероссийского опроса общественного мнения и фокус-групповых дискуссий мы устанавливаем, что логика атрибуции ответственности по-разному проявляется в оценках эффективности работы президента, правительства и думы. Результаты нашего исследования показывают, что коллективные органы с непопулярными политиками - Государственная дума и правительство- наделяются наибольшей ответственностью за ухудшение уровня жизни. Эти институты «принимают удар» на себя и становятся символическим виновником неэффективной политики и ее последствий. На фоне высокого уровня фрустрации и недовольства работой думы и правительства, фигура президента остается вне критики граждан. Результаты его работы либо редко, либо вообще не связывают с кризисом. Анализ фокус-групповых дискуссий показал, что недостаток когнитивных ресурсов, институциальная непрозрачность и низкое качество политически релевантной информации ограничивают возможности людей адекватно
\end{abstract}

Елена Викторовна Сироткина- магистр политологии, мл. н. с., Лаборатория сравнительных социальных исследований, Национальный исследовательский университет «Высшая школа экономики», Москва, Россия. Электронная почта: sirotkina.elena@gmail.com

Андрей Владимирович Семенов- к. полит. наук, ст.н.с., Центр сравнительных исторических и политических исследований; доцент, кафедра политических наук, Пермский государственный национальный исследовательский университет, Пермь, Россия. Электронная почта: andreysemenov@comparativestudies.ru 
оценивать работу органов власти и наделять ответственностью за политический курс. Проблемы с адекватной атрибуцией ответственности, в свою очередь, имеют серьезные следствия с точки зрения подотчетности и изменения политического курса. Не представляя кто несет ответственность за политические решения, люди не могут определить необходимые изменения в направлении политических действий. В таком случае не только «институциальная ясность» в распределении полномочий будет играть важную роль, но и качество медийной среды, выступающей основным проводником сведений о политике.

Ключевые слова: экономический кризис, атрибуция ответственности, политические институты, подотчетность, эффективность власти

DOI: 10.17323/727-0634-2019-17-2-191-206

Эмпирические исследования показывают, что экономический кризис часто становится причиной смены правительств в демократических режимах и кризиса политической системы в целом в недемократических (Finkel et al. 1989; Remmer 1990; Gasiorowski 1995). В авторитарных режимах, где подотчетность правительств посредством электоральной демократии ограничена, сокращение объема доступных ресурсов серьезно сказывается на устойчивости режима, однако не обязательно ведет к его смене (Haggard, Kaufman 1995). Другие исследования демонстрируют, что степень интегрированности национальной экономики в мировую, а также экономическая состоятельность правящей элиты являются более важными факторами, обуславливающими политические последствия экономического кризиса в автократиях, чем спад в экономике (Pepinsky 2009, 2012). В целом существующая литература признает значимость механизмов атрибуции ответственности за экономический кризис правительству, но редко обращается к этой теме в контексте электоральных автократий и фокусируется на широких кросс-национальных сравнениях (Tang et al. 2017; Tanneberg et al. 2013). Исследования, которые бы демонстрировали связь между экономическим кризисом и атрибуцией ответственности на индивидуальном или микроуровне встречаются еще реже (ср.: Rosenfeld 2018).

Пример России представляется важным случаем для выявления связи между экономическими проблемами и оценкой эффективности власти. Резкие изменения экономической ситуации здесь сопровождались политической нестабильностью: кризис советской модели экономики конца 1980-х-начала 1990-х гг. привел к падению коммунистического режима, кризис 1998 г. вызвал массовый протест со стороны населения и изменения в системе государственного управления, а глобальный финансово-экономический кризис 2008 г. привел к переоценке гражданами «социального контракта» с властью (Chaisty, Whitfield 2012). Экономисты отмечают, что несмотря на восстановление российской экономики в 2010-2012 гг., начиная с 2013 г. наблюдаются признаки очередного структурного кризиса 
или стагнации (Guriev 2015). Ряд экспертов связывают фундаментальные причины экономического кризиса с политикой президента и правительства, «присоединением» Крыма и, как следствие, бегством капитала, падением инвестиционной привлекательности России и политикой обмена санкциями (см.: Алексашенко 2016; Московский Центр Карнеги 2015).

Кажущаяся очевидной экспертам связь между действиями власти и ухудшением экономической ситуации, однако не находит отражения в общественном мнении. Рейтинги одобрения президента, премьер-министра и правительства продолжали оставаться на высоком уровне в 2014-2017 гг. (Аналитический центр Юрия Левады 2017). Почему не происходит трансляции объективных экономических условий в недовольство работой органов власти? Наш аргумент заключается в том, что оценка эффективности и уровень поддержки институтов власти связаны с особенностями атрибуции ответственности- способностью граждан определять политических агентов и институты, оказывающие значимое воздействие на ту или иную сферу общественной жизни (экономику, медицину, образование, внешнюю политику).

Наша исследовательская повестка включает следующие вопросы: кому (каким институтам) россияне склонны ставить в заслугу «позитивные события» в стране, а кого обвинять в провалах? Связывается ли экономический кризис с неэффективностью власти в принципе и как это отражается на поддержке парламента, президента и правительства? Для ответа на эти вопросы в первой части статьи мы рассмотрим существующие объяснительные модели влияния экономического кризиса на поддержку власти, а во второй- представим результаты исследования, основанного на репрезентативном массовом опросе и серии фокус-групп в регионах, которые проводились в августе 2016 г. и в июне-августе 2017 г., соответственно.

\section{Влияние экономического кризиса на поддержку власти в России}

Политические последствия изменений в экономике- одна из наиболее разработанных тем в социальных науках, особенно в рамках так называемой экономической теории голосования. Избиратели осуществляют свой выбор, находясь не в вакууме, а в разнообразных политико-институциальных условиях, которые могут способствовать или препятствовать более четкой идентификации ответственных за происходящее в экономике (Hobolt et al. 2013). Политические элиты также реагируют на кризис и могут прибегать к тактике «перенаправления»/ «распределения» ответственности-blame-shifting/blame-sharing (Magalhães 2014). Избиратели могут «наказывать» политиков за последствия, которые не вытекали из их действий, например, за последствия природных катастроф-впрочем, как и за политические решения, к которым политики не имеют отношения (Achen, Bartels 2016). Наконец, в ситуации со множеством потенциальных 
объектов обвинения распределение ответственности между ними не представляет собой «игру с нулевой суммой»: не обязательно уменьшение ответственности одного игрока автоматически ведет к увеличению ответственности другого (Rudolph 2003 a, 2003 b).

Экономическая теория голосования неоднократно применялась к российскому контексту. Даниел Трейсман (Treisman 2011, 2014) доказал, что оценка экономических условий последовательно оказывалась значимой для оценки президентской власти как Б.Н. Ельцина, так и В.В. Путина. Экономический кризис 2008 г. стал основанием для роста коллективных протестов, некоторые из которых имели политическую окраску (Семенов 2016). Тем не менее несмотря на общий тренд снижения рейтинга президента в период экономических кризисов, на фоне внешнеполитических успехов россияне оценивали эффективность власти, как если бы кризиса не было. Скорее всего это объясняется массированной кампанией в СМИ и эффектом «единения вокруг знамени», хорошо известном по опыту США (Mueller 1970, 1973). В этом смысле важна не экономика сама по себе, а то, как правительство отвечает на внешние угрозы в период экономических кризисов и подъемов- победоносная внешняя политика мобилизует граждан вокруг лидеров страны (Mishler, Willerton 2003: 134). Рейтинги власти часто оказываются нечувствительными к экономическим спадам, а очень высокий рейтинг Путина отражает реальную высокую поддержку политики президента (Rose et al. 2004). Гораздо меньше внимания исследователи обращали на факторы популярности других институтов государственной власти - парламента и правительства. Они остаются в тени президента, что в том числе отражено и в рассматриваемом поле.

Наша исследовательская проблема распадается на две части: с одной стороны, необходимо установить, что экономический кризис влияет на оценку эффективности власти в России, с другой-разобраться, как граждане атрибутируют ответственность за него, если это происходит. Для решения первой задачи мы использовали данные массового опроса населения, а для решения второй- данные фокус-групповых дискуссий, которые позволяют проследить логику и глубину связи между экономическим кризисом и механизмами атрибуции ответственности за него.

\section{Оценка эффективности российской власти В ситуации экономического кризиса}

\section{Результаты массового опроса}

Массовый опрос граждан проведен в августе 2016 г. социологическим центром Юрия Левады (репрезентативная выборка, N=1601), его материалы позволяют зафиксировать эффект воздействия экономического кризиса на оценку эффективности власти на агрегированном уровне. 
Рисунки 1-3. Распределение оценок эффективности деятельности думы, президента и правительства России по ответам, где 1 - «совершенно неэффективно» и 4 «абсолютно эффективно» в процентах. Данные: Левада-Центр (2016 г.)
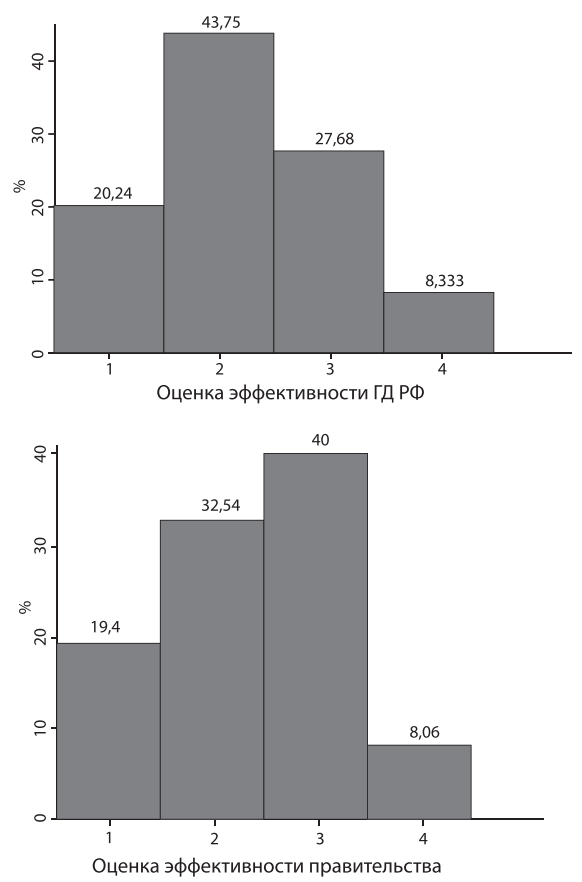

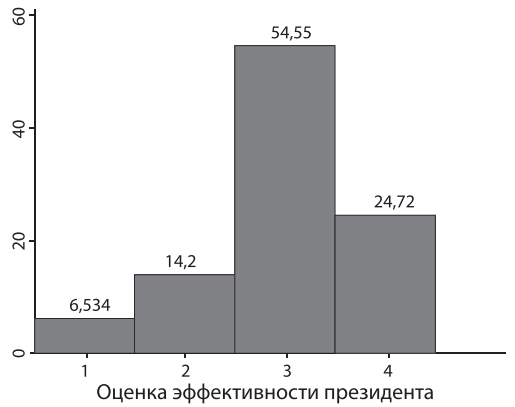

Эффективность Государственной думы оценивается респондентами скорее негативно: $60 \%$ считает, что она работает в целом неэффективно, $32 \%$ - дума работает скорее эффективно и $8 \%$ признают ее деятельность очень эффективной ${ }^{1}$. Оценка правительства несколько более позитивная: немногим больше половины (52\%) не считают его эффективным, тогда как доля тех, кто думает, что правительство более-менее справляется со своими обязанностями достигает $43 \%$. Деятельность президента, в отличии от думы и правительства, подавляющим большинством оценивается как эффективная: 56\% находят ее «скорее эффективной» и еще $23 \%$ - «очень эффективной» (рис. 1-3). Важно понимать, что оценка эффективности происходила в условиях продолжающейся позитивной оценки внешнеполитических действий президента Путина после присоединения Крыма: судя по опросу, для большинства россиян это событие символизировало возвращение стране статуса одного из ведущих игроков на международной арене, а реакция стран Запада подтвердила и усилила представления о международной среде как источнике опасности. Мобилизовав национальные чувства и используя риторику безопасности, президент выиграл от существовавших в массовом сознании установок.

\footnotetext{
${ }^{1}$ Респондентам задавался вопрос: «Как вы считаете, насколько эффективно действует сейчас Государственная Дума/Президент России Владимир Путин/Правительство России?». Варианты ответа на данный вопрос включали «очень эффективно, «скорее эффективно», «скорее неэффективно», «очень неэффективно» и «затрудняюсь ответить».
} 

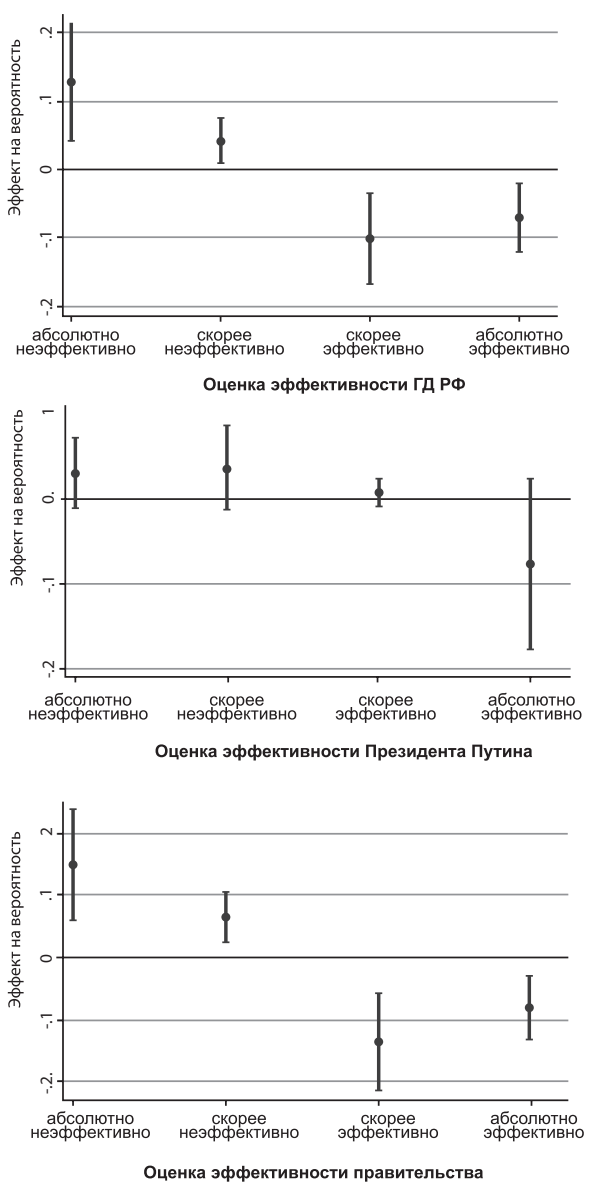

Рисунки 4-6. Оценка средних предельных эффектов для объясняющего фактора (признание экономического кризиса) на оценки эффективности ГД РФ, президента и правительства соответственно
Для оценки влияния связи кризиса и представлений об эффективности действий думы, правительства и президента использовался следующий вопрос: «Некоторые эксперты считают, что Россия сейчас переживает экономический кризис. Согласны ли вы с этим утверждением?» Предполагался выбор из двух ответов: «да, согласен» и «нет, не согласен». Подавляющее большинство опрошенных признали, что экономический кризис существует (85\%). Сравнение оценок эффективности каждого из институтов между группами согласных и несогласных с утверждением о кризисе показывает, что средние оценки парламента, правительства и президента выше в группе респондентов, которые не признают экономический кризис (рис. 4-6).

Чтобы определить значимость влияния признания экономического кризиса на оценку эффективности власти, мы построили модели порядковой пробит-регрессии, в которых зависимой переменной выступает эффективность каждого из исследуемых институтов власти (по шкале Ликерта), а ключевая независимая переменная - согласие или несогласие с тем, что Россия переживает экономический кризис. Для всех спецификаций мы использовали следующие контрольные переменные: пол, возраст, уровень образования, семейный доход и размер населенного пункта. Для интерпретации результатов порядковых пробит-регрессий мы вычисляем предельные эффекты для объясняющих переменных. Результаты (табл. 1) показывают, что признание экономического кризиса связано со снижением вероятности получения оценки «абсолютно эффективно» для Государственной думы на 0.07 и для правительства на 0.08. Признание кризиса также связано со снижением оценки «скорее эффективно» на 0.1 балла для Государственной 
думы и на 0.14 для правительства и, соответственно, повышает вероятность неудовлетворительных оценок. Оценка эффективности президента в целом имеет похожий принцип (среди тех, кто признает кризис, больше вероятность снижения оценки), однако этот эффект очень слабый и не преодолевает конвенциональных значений статистической значимости.

Таблица 1

Оценка средних предельных эффектов для объясняющего фактора (признание экономического кризиса) на вероятность оценки эффективности органов власти

\begin{tabular}{|c|c|c|c|}
\hline $\begin{array}{c}\text { Предсказанные } \\
\text { вероятности }\end{array}$ & $\begin{array}{c}\text { (1) } \\
\text { Предельные } \\
\text { эффекты } \\
\text { для оценки } \\
\text { эффективности } \\
\text { ГД РФ }\end{array}$ & $\begin{array}{c}\text { (2) } \\
\text { Предельные } \\
\text { эффекты } \\
\text { для оценки } \\
\text { эффективности } \\
\text { президента }\end{array}$ & $\begin{array}{c}\text { (3) } \\
\text { Предельные } \\
\text { эффекты } \\
\text { для оценки } \\
\text { эффективности } \\
\text { правительства }\end{array}$ \\
\hline Абсолютно неэффективно & $\begin{array}{c}0.128 * * * \\
(0.0443)\end{array}$ & $\begin{array}{r}0.0307 \\
(0.0212)\end{array}$ & $\begin{array}{c}0.150 * * * \\
(0.0452)\end{array}$ \\
\hline Скорее неэффективно & $\begin{array}{r}0.0425^{* *} \\
(0.0169)\end{array}$ & $\begin{array}{r}0.0372 \\
(0.0255)\end{array}$ & $\begin{array}{r}0.0654 * * * \\
(0.0204)\end{array}$ \\
\hline Скорее эффективно & $\begin{array}{r}-0.1000 * * * \\
(0.0342)\end{array}$ & $\begin{array}{r}0.00787 \\
(0.00821)\end{array}$ & $\begin{array}{r}-0.135 * * * \\
(0.0398)\end{array}$ \\
\hline Абсолютно эффективно & $\begin{array}{r}-0.0702 * * * \\
(0.0257)\end{array}$ & $\begin{array}{l}-0.0758 \\
(0.0510)\end{array}$ & $\begin{array}{r}-0.0809^{* * *} \\
(0.0260)\end{array}$ \\
\hline $\mathrm{N}$ & 333 & 348 & 332 \\
\hline
\end{tabular}

В скобках стандартные ошибки; *,**,*** указывают на значимость на уровне 10 процентов, 5 процентов и 1 процента соответственно

Таким образом, наше предположение о том, что на индивидуальном уровне граждане «наказывают» власть за экономический кризис нашло подтверждение, как и представление о дифференцированной атрибуции ответственности: президент оказывается вне критики, тогда как Государственная дума и правительство получают низкую оценку эффективности. Срезовый характер исследования не позволяет сделать вывод о причинноследственной связи, поскольку можно предположить наличие латентной ненаблюдаемой характеристики респондентов (например, чувствительности к экономической политике, которая может влиять на критичность и восприимчивость к кризису одновременно). Чтобы разобраться, какие рассуждения лежат в основе атрибуции ответственности обратимся к анализу результатов фокус-групповых дискуссий. 


\section{Результаты фокус-групп}

Фокус-групповые обсуждения экономического кризиса и ответственности за него власти проводились в период с июня по август 2017 г. Всего проведено шесть фокус-групп в четырех городах: Пермь (2), Санкт-Петербург (2), Москва (1) и Саранск (1). Состав и места проведения фокус-групп позволили обеспечить достаточную вариацию контекстов фокус-групповых дискуссий, а также сравнить их по линиям «столичные города-регионы», «экономически развитый регион (Пермский край)- экономически отстающий (республика Мордовия)», «студенческая молодежь- общая аудитория» (Пермский край), «предпочитающие телевидение в качестве основного источника- не смотрящие телевизор» (Санкт-Петербург). Описание фокусгрупп представлено в таблице 2 .

Таблииа 2

Основные характеристики фокус-групповых дискуссий

\begin{tabular}{|c|c|c|c|}
\hline $\begin{array}{c}\text { Дата } \\
\text { проведения }\end{array}$ & $\begin{array}{c}\text { Место } \\
\text { проведения }\end{array}$ & $\begin{array}{c}\text { Кол-во } \\
\text { участников }\end{array}$ & Особенности состава \\
\hline 19.06.2017 & Пермь & 8 & Студенческая аудитория \\
\hline 28.06 .2017 & Пермь & 10 & Общая аудитория \\
\hline 02.07.2017 & Саранск & 10 & Общая аудитория \\
\hline 04.07.2017 & Москва & 12 & Общая аудитория \\
\hline 09.08.2017 & Санкт-Петербург & 9 & $\begin{array}{l}\text { Общая аудитория, не смотрят } \\
\text { телевизор }\end{array}$ \\
\hline 12.08.2017 & Санкт-Петербург & 11 & Общая аудитория, смотрят телевизор \\
\hline
\end{tabular}

В целом фокус-групповые дискуссии показывают, что оценка эффективности и атрибуция ответственности являются для граждан когнитивно затратными процессами. Во-первых, многим участникам фокус-групп оказалось трудно идентифицировать конкретных носителей власти. В первую очередь назывались представители власти, с которыми участники дискуссий непосредственно сталкивались в своей жизни; например, работники сферы медицины или образования называли профильные министерства, достаточно часто вспоминали муниципальные органы власти в связи с их (не)исполнением обязанностей по поддержанию инфраструктуры. Государственная дума и правительство упоминались редко. Метафорически одна из участниц обозначила власть как любых агентов, «которые могут сделать тебе больно» (Ж., 40 лет, СПб-2). Дистанция власти от граждан- повторяющийся мотив всех фокус-групп. Вопросы 
наделения политической ответственностью также оценивались участниками как трудные в связи с тем, что обычно они не следят и не обсуждают политические темы, чувствуют себя недостаточно компетентными в вопросах оценки политических процессов, а также не имеют релевантного опыта оценки. Типичный ответ на многие вопросы фокус-группы: «Я очень плохо разбираюсь в политике». Политическая сфера для российских граждан представляется закрытой и непонятной.

В результате вопрос об оценке эффективности власти часто встречал непонимание: респонденты просили предоставить какие-либо общие критерии и без них отказывались оценивать. Попытка ввести пятибалльную шкалу приводила к тому, что участники присоединялись к той оценке, которая была высказана первой. Трудным оказалась и дифференциация оценок между органами власти. Тем не менее при формулировке вопроса в рамках порядковой шкалы (оценить эффективность власти относительно друг друга), ответы напоминали данные массового опроса: президент всегда оценивался выше, правительство оказалось на втором месте, хуже всего оценивалась эффективность работы Государственной думы.

Президента большинство участников оценивают однозначно положительно, легко идентифицируют как субъекта ответственности, атрибутируют ему большую часть результатов политического курса в стране. Редкие негативные отзывы касаются вопросов коррупции, монополизации власти, ручного стиля управления, недостаточного контроля над чиновниками и олигархами. Зачастую респонденты «снимают» ответственность с президента: «B данной ситуации у нас большое государство, президента обвинять, я думаю, что нецелесообразно, потому что он везде не успевает, видимо, порядок навести» (М., 40 лет, Пермь); «У него минус большой- то, что он создал вокруг себя бездельников» (Ж., 55 лет, Саранск); «Президент-да, ведет хорошую внутреннюю и внешнюю политику. Но один он сделать за всех не может» (Ж., 52 года, Москва); «По моему мнению, свою главную функцию президент исполняет, поэтому 4 [по пятибалльной шкале], единственное, что плохо следит за Государственной думой и правительством» (Ж., 20 лет, Москва).

Правительством и Государственной думой, в отличие от президента, почти всегда недовольны. Их наделяют ответственностью за внутреннюю политику и за экономический кризис: «Госдума и правительство не выполняют свои функции, они должны держать страну, они опускают страну» (Ж., 20 лет, Москва), «почему к правительству плохо отношусь, это как говорится, его правые руки, потому что как раз и занимается слежкой за выполнением законов. В итоге они ничем не занимаются» (М., 25 лет, Саранск), «тоже то, что много обещают, много, но не делают, чего хотят. Планы ставят, а цуели, то есть, нет изели, какой-то определённой, достигнутой, на мой взгляд так» (Ж., 31 лет, Пермь-2). Часто участники недовольны профильным министерством, с работой которого они регулярно сталкиваются. 
На фоне низких оценок работы исполнительной и законодательной ветвей власти сам экономический кризис получает разные оценки. Вопервых, для многих оказалось непонятным содержание самого понятия «экономический кризис», некоторые затруднились определить временные границы этого явления. Так, в качестве кризисных упоминались 1990-егг., 2008 г., события 2014 г. (обвал рубля). Позиции по поводу восприятия кризиса можно разделить по двум основаниям: был ли он в принципе и насколько удалось его преодолеть: часть респондентов считает, что кризиса в принципе не было, скорее можно говорить о трудностях развития. Часть участников отметили, что кризис был и он в целом преодолен. Однозначных оценок участники старались избегать, маркируя свои суждения такими наречиями как «возможно», «мне кажется», «скорее». Некоторые участники считают, что кризис- это перманентное состояние экономики России: «[Кризис] есть, был и будет, еще не знаю, сколько времени» (Ж., 58 лет, Пермь-1). Точка отсчета кризиса неясна, респонденты второй фокус-группы в Перми предложили считать 1990-е гг. или 20072008 гг. началом кризиса, а текущее состояние - его отголосками: «20072008 годы, это мировой кризис, это признанный факт, это не обсуждается. А 2014-й год, он никак, ничего» (М., 57 лет, Пермь-2). Такая же оценка прозвучала на фокус-группе в Москве: конец 1990-х гг., либо 2007-2008 гг. являются отсеченной точкой для кризисных явлений. Многие участники, особенно из групп с низким социально-экономическим статусом, отметили, что их положение начало ухудшаться еще до 2014 г., либо было неустойчивым весь постсоветский период.

Из наиболее ярких проявлений кризиса участники отмечали увольнения (в том числе родственников) и появившийся страх безработицы, рост цен, трудности с выездом за границу. Одна участница отметила, что кризис отобрал все ее сбережения. Во многом он воспринимается как очень растянутый во времени процесс, последствия которого не проявились до конца и еще не преодолены: «Но я еще не могу до кониа сказать, вышли ли мы из этого кризиса. Да, такая самая тяжелая часть она пройдена была в 15,14,12-х годах, но для России, сейчас, мне кажется, экономика больще отрицательна» (М., 18 лет, Пермь-1). Наконец, есть и точка зрения, что экономический кризис-это нормальное постоянное, даже несколько надуманное явление: «Кризис потребительский: хлеба и зрелищ людям нужно - и все» (Ж., 46 лет, СПб-2).

В результате связь между кризисными явлениями в экономике и ответственностью власти выглядит неустойчивой: парламент воспринимается как институт «коллективной безответственности», правительство выступает центром принятия решений, но фактически подчиняется президенту, который наделен полнотой власти, и при этом избегает всякой ответственности. Важным эмпирическим наблюдением представляется наличие бо́льшей фрустрации участников с низким социально-экономическим статусом. 
Экономический кризис для них проявляется в сокращении и без того небольшого спектра возможностей для улучшения условий жизни, некоторые воспринимают весь постсоветский период как борьбу за выживание и в этой связи кризис кажется им перманентным. Участники с более высоким социально-экономическим статусом придерживаются схожих взглядов, но с большей осторожностью подходят к оценке работы власти, чаще указывают на сложность разработки политического курса, а также на то, что внутри правительства или думы существуют более эффективные и менее эффективные органы. Иными словами, наличие дополнительных ресурсов (образования или дохода) зачастую ведет не к большей критике власти, а к более дифференцированной оценке ее эффективности.

\section{Заключение}

Связь между экономическим кризисом и оценкой эффективности власти в электоральных автократиях, во-первых, непросто установить, во-вторых, на индивидуальном уровне она осложняется набором медиаторов. На агрегированном уровне оценка эффективности Государственной думы и правительства оказывается чувствительной к признанию экономического кризиса, в то время как на оценку эффективности президента признание экономического кризиса не влияет. Этот вывод согласуется с литературой о том, что в электоральных автократиях такие коллективные органы власти выполняют важную функцию «молниеотвода»-lightning rod (Herring 1940). Эти институты «принимают удар» на себя и становятся символическим виновником неэффективной политики и ее последствий. На их фоне работа президента выглядит более успешной.

Несмотря на то, что россияне в целом ощущают последствия экономического кризиса, однозначно определить его временные границы в ходе фокус-групп они не смогли. Кризис, таким образом, скорее ассоциируется с общим ощущением разрыва между притязаниями и наличным уровнем удовлетворения потребностей, а не с конкретными макроэкономическими показателями. Низкий уровень жизни (для пожилых граждан зачастуюв ретроспективном сравнении с советским прошлым) выступает основным индикатором кризиса. Таким же образом участникам фокус-групп было трудно определить связь между действиями власти (политическим курсом) и экономической реальностью. Частые ссылки на недостаток знания в этой области лишь отчасти можно приписать скромности или стремлению «не оказаться в дураках», они вполне отражают общий уровень когнитивных ресурсов населения.

Это исследование имеет и практические следствия. Наша работа показывает, что для правильной атрибуции необходимо понимание того, как работают политические институты, как различаются их полномочия и функции. Не представляя, кто несет ответственность за политические решения, 
люди не могут определить, что и как необходимо изменить в курсе политических действий. Очевидно, что в таком случае будет играть роль не только «институциальная ясность» в распределении полномочий, но и качество медийной среды- основного проводника сведений о политике.

\section{Выражение признательности}

Статья написана в рамках исследования «Политика в тяжелые времена»: методы обеспечения политической легитимности власти в России» при поддержке гранта РГНФ № 16-33-01049 а2. Статья подготовлена в ходе проведения работы в рамках Программы фундаментальных исследований Национального исследовательского университета «Высшая школа экономики» (НИУ ВШЭ) и с использованием средств субсидии в рамках государственной поддержки ведущих университетов Российской Федерации «5-100».

\section{Список источников}

Алексашенко С. (2016) Что делать с экономикой после 2018 года? Pro et Contra, (6). Доступно по ссылке: http://www.counter-point.org/wp-content/uploads/2016/12/aleksashenko_counterpoint6.pdf (дата обращения: 18 мая 2019).

Аналитический центр Юрия Левады (2017) Одобрение органов власти. Доступно по ссылке: https://www.levada.ru/indikatory/odobrenie-organov-vlasti/ (дата обращения: 1 ноября 2017).

Московский Центр Карнеги (2015) Mы создали страну-наркомана. Доступно по ссылке: http://carnegie.ru/2015/08/26/ru-pub-61128 (дата обращения: 1 ноября 2017).

Семенов А.В. (2016) От экономического кризиса к политическому? Динамика протестных требований в российских регионах (2008-2012 гг.). Журнал исследований социальной политики, 2 (14): 151-166.

Achen C., Bartels L. (2016) Democracy for Realists: Why Elections Do Not Produce Responsive Government. Princeton: Princeton university press.

Chaisty P., Whitefield S. (2012) The Effects of the Global Financial Crisis on Russian Political Attitudes. Post-Soviet Affairs, 28 (2): 187-208.

Finkel S. E., Muller E. N., Seligson M. A. (1989) Economic Crisis, Incumbent Performance and Regime Support: A Comparison of Longitudinal Data from West Germany and Costa Rica. British Journal of Political Science, 19 (3): 329-351.

Gasiorowski M. (1995) Economic Crisis and Political Regime Change: An Event History Analysis. American Political Science Review, 89 (4): 882-97.

Guriev S. (2015) Political Origins and Implications of the Economic Crisis in Russia. In: L. Aron (ed.) In Putin's Russia: How it Rose, How it is Maintained, and How it Might End. Washington, DC: American Enterprise Institute: 8-35.

Herring P. (1940) Presidential Leadership. New York: Farrar \& Rinehart. 
Haggard S., Kaufman R. (1995) The Political Economy of Democratic Transitions. Princeton: Princeton University Press.

Hobolt S., Tilley J., Banducci S. (2013) Clarity of Responsibility: How Government Cohesion Conditions Performance Voting. European Journal of Political Research, 52 (2): 164-187.

Magalhães P. (2014) The Elections of the Great Recession in Portugal: Performance Voting under a Blurred Responsibility for the Economy. Journal of Elections, Public Opinion \& Parties, 24 (2): 180-202.

Mishler W., Willerton W. (2003) The Dynamics of Presidential Popularity in Post-Communist Russia: Cultural Imperative versus Neo-Institutional Choice? Journal of Politics, 65 (1): 111-141.

Mueller J. (1970) Presidential Popularity from Truman to Johnson. The American Political Science Review, 64 (1): 18-34.

Mueller J. (1973) War, Presidents, and Public Opinion. New York: John Wiley \& Sons.

Pepinsky T. (2009) Economic Crises and the Breakdown of Authoritarian Regimes: Indonesia and Malaysia in Comparative Perspective. Cambridge: Cambridge University Press.

Pepinsky T. (2012) The Global Economic Crisis and the Politics of Non-Transitions. Government and Opposition, 47 (2): 135-161.

Remmer K. L. (1990) Democracy and Economic Crisis: The Latin American Experience. World Politics, 42 (3): 315-335.

Rose R., Munro N., Mishler W. (2004) Resigned Acceptance of an Incomplete Democracy: Russia's Political Equilibrium. Post-Soviet Affairs, 20 (3): 195-218.

Rosenfeld B. (2018) The Popularity Costs of Economic Crisis under Electoral Authoritarianism: Evidence from Russia. American Journal of Political Science, 62 (2):382-397.

Rudolph T. J. (2003a) Who's Responsible for the Economy? The Formation and Consequences of Responsibility Attributions. American Journal of Political Science, 47 (4): 698-713.

Rudolph T. J. (2003b) Institutional Context and the Assignment of Political Responsibility. Journal of Politics, 65 (1): 190-215.

Tang M., Huhe N., Zhou Q. (2017) Contingent Democratization: When Do Economic Crises Matter? British Journal of Political Science, 47 (1): 71-90.

Tanneberg D., Stefes C., Merkel W. (2013) Hard Times and Regime Failure: Autocratic Responses to Economic Downturns. Contemporary Politics, 19 (1): 115-129.

Treisman D. (2011) Presidential Popularity in a Hybrid Regime: Russia under Yeltsin and Putin. American Journal of Political Science, 55 (3): 590-609.

Treisman D. (2014) Putin's Popularity Since 2010: Why did Support for the Kremlin Plunge, Then Stabilize? Post-Soviet Affairs, 30 (5): 370-388. 
Elena Sirotkina, Andrey Semenov

\title{
ECONOMIC CRISIS AND THE ASSESSMENT OF PUBLIC EFFECTIVENESS: WHO BEARS RESPONSIBILITY FOR THE ECONOMIC DOWNTURN IN RUSSIA?
}

\begin{abstract}
Should public authorities be blamed for the economic downturn and its consequences? If so, which political authorities in particular are singled out and which escape from being held accountable? We assume that the basis for the observed gap between the worsening economic conditions and the approval ratings of the president, the government, and the parliament is the mechanism of responsibility attribution: the ability of citizens to identify decision-making centers and link the implemented policy to the changes in living conditions. Lack of cognitive resources, institutional opaqueness, and the poor quality of politically relevant information can hamper the accurate attribution of blame, with corresponding effects of the evaluation of performance. Our data show that collective bodies with unpopular politicians, such as the State Duma and the government, are given the lion's share of the blame for the deterioration in living standards. In comparison with them, the president is perceived to be the winner and thereby avoids blame for the crisis in the economy. At the same time, the study shows a high level of citizen frustration and dissatisfaction with the effectiveness of public authorities, in particular the low responsiveness of state institutions. The failure to accurately attribute blame, in turn, poses a serious danger to the authorities' accountability and policy changes. Without a clear understanding of who takes responsibility for particular political decisions, one cannot be sure whom to blame for poor policies. Obviously, in such a case, not only 'institutional clarity' in the distribution of powers, but also the quality of the media environment, will play a major part, given its mediating role on responsibility attribution.
\end{abstract}

Keywords: economic crisis, attribution of responsibility, political institutions, accountability, effectiveness of authority

DOI: 10.17323/727-0634-2019-17-2-191-206

\section{References}

Achen C., Bartels L. (2016) Democracy for Realists: Why Elections do not Produce Responsive Government. Princeton: Princeton university press.

Elena Sirotkina- Master of Science (MSc) in Political Science, Junior Research Fellow in the Laboratory for Comparative Social Research, National Research University Higher School of Economics, Moscow, Russian Federation. Email:_sirotkina.elena@gmail.com

Andrey Semenov - Kandidat Nauk (PhD) in Political Science, research fellow, Center for Comparative History and Politics Studies; associate professor, Department of Political Sciences, Perm State National Research University, Perm, Russian Federation. Email: andreysemenov@, comparativestudies.ru 
Aleksashenko S. (2016) Chto delat's ekonomikoy posle 2018 goda? [What to Do with the Economy after 2018?] Pro et Contra. (6). Available at: http://www.counter-point.org/wpcontent/uploads/2016/12/aleksashenko_counterpoint6.pdf (accessed May 18, 2019)

Carnegie Moscow Center (2015) My sozdali stranu-narkomana [We Created a Drug-Addicted Country]. Available at: http://carnegie.ru/2015/08/26/ru-pub-61128 (accessed 1 November 2017).

Chaisty P., Whitefield S. (2012) The Effects of the Global Financial Crisis on Russian Political Attitudes. Post-Soviet Affairs, 28 (2): 187-208.

Finkel S.E., Muller E. N., Seligson M. A. (1989) Economic Crisis, Incumbent Performance and Regime Support: A Comparison of Longitudinal Data from West Germany and Costa Rica. British Journal of Political Science, 19 (3):329-351.

Gasiorowski M. (1995) Economic Crisis and Political Regime Change: An Event History Analysis. American Political Science Review, 89 (4): 882-97.

Guriev S. (2015) Political Origins and Implications of the Economic Crisis in Russia. In: L. Aron (ed.) In Putin's Russia: How it Rose, How it is Maintained, and How It Might End. Washington DC: American Enterprise Institute: 8-35.

Herring P. (1940) Presidential Leadership. New York: Farrar \& Rinehart.

Haggard S., Kaufman R. (1995) The Political Economy of Democratic Transitions. Princeton: Princeton University Press.

Hobolt S., Tilley J., Banducci S. (2013) Clarity of Responsibility: How Government Cohesion Conditions Performance Voting. European Journal of Political Research, 52 (2): 164-187.

Levada-Center Website (2017) Odobreniye organov vlasti [Approval of Public Authorities]. Available at: https://www.levada.ru/indikatory/odobrenie-organov-vlasti (accessed 1 November 2017).

Magalhães P. (2014) The Elections of the Great Recession in Portugal: Performance Voting under a Blurred Responsibility for the Economy. Journal of Elections, Public Opinion \& Parties, 24 (2): 180-202.

Mishler W., Willerton W. (2003) The Dynamics of Presidential Popularity in Post-Communist Russia: Cultural Imperative versus Neo-Institutional Choice? Journal of Politics, 65 (1): 111-141.

Mueller J. (1970) Presidential Popularity from Truman to Johnson. The American Political Science Review, 64 (1): 18-34.

Mueller J. (1973) War, Presidents, and Public Opinion, New York: John Wiley \& Sons.

Pepinsky T. (2009) Economic Crises and the Breakdown of Authoritarian Regimes: Indonesia and Malaysia in Comparative Perspective. Cambridge: Cambridge University Press.

Pepinsky T. (2012) The Global Economic Crisis and the Politics of Non-Transitions. Government and Opposition, 47 (2): 135-161.

Remmer K. L. (1990) Democracy and Economic Crisis: The Latin American Experience. World Politics, 42 (3): 315-335. 
Rose R., Munro N., Mishler W. (2004) Resigned Acceptance of an Incomplete Democracy: Russia's Political Equilibrium. Post-Soviet Affairs, 20 (3): 195-218.

Rosenfeld B. (2018) The Popularity Costs of Economic Crisis under Electoral Authoritarianism: Evidence from Russia. American Journal of Political Science, 62 (2):382-397.

Rudolph T.J. (2003a) Who's Responsible for the Economy? The Formation and Consequences of Responsibility Attributions. American Journal of Political Science, 47 (4): 698-713.

Rudolph T. J. (2003b) Institutional Context and the Assignment of Political Responsibility. Journal of Politics, 65 (1): 190-215.

Semenov A. V. (2016) Ot ekonomicheskogo krizisa k politicheskomu? Dinamika protestnykh trebovaniy v rossiyskikh regionakh (2008-2012 gg.) [From Economic to Political Crisis?_Dynamics of Contention in Russian Regions (2008-2012)]. Zhurnal issledovaniy sotsial'noy politiki [The Journal of Social Policy Studies], 14 (2): 151-166.

Tang M., Huhe N., Zhou Q. (2017) Contingent Democratization: When Do Economic Crises Matter? British Journal of Political Science, 47 (1):71-90.

Tanneberg D., Stefes C., Merkel W. (2013) Hard Times and Regime Failure: Autocratic Responses to Economic Downturns. Contemporary Politics, 19 (1): 115-129.

Treisman D. (2011) Presidential Popularity in a Hybrid Regime: Russia under Yeltsin and Putin. American Journal of Political Science, 55 (3): 590-609.

Treisman D. (2014) Putin's Popularity Since 2010: Why Did Support for the Kremlin Plunge, then Stabilize? Post-Soviet Affairs, 30 (5):370-388. 